\title{
Influence of posteromedial corner injuries on clinical outcome and second-look arthroscopic findings after allograft transtibial anterior cruciate ligament reconstruction
}

\author{
Jun-Young Yoo, Hee-Gon Park ${ }^{*}$ and Soon-Min Kwon
}

\begin{abstract}
Background: The purpose of this study was to evaluate the influence of posterior medial corner (PMC) injuries on clinical outcome and second-look arthroscopic findings after anterior cruciate ligament (ACL) reconstruction.

Methods: Seventy-eight consecutive patients underwent a second-look arthroscopic surgery after ACL reconstruction and magnetic resonance imaging (MRI) examination of the PMC. The patients were divided into a PMC intact group $(n=42)$ and a PMC injured group $(n=36)$. The stability and clinical outcomes were evaluated using the Lachman test, pivot-shift test, a KT-2000 arthrometer, and the Lysholm knee scoring scale. Graft tension and synovial coverage were evaluated in second-look arthroscopy.

Results: The clinical function showed no significant differences regarding PMC injury. Although the graft tendon tension revealed no significant differences $(p=0.141)$, the second-look arthroscopic findings indicated that the PMC intact group showed better synovial coverage compared to the PMC injured group ( $p=0.012)$.

Conclusion: Patients who injured the PMC had poor synovial coverage as assessed by second-look arthroscopic findings after transtibial $A C L$ reconstruction, even though clinical outcomes and stability showed no significant differences.
\end{abstract}

Keywords: Anterior cruciate ligament, Knee, Reconstruction, Posteromedial corner

\section{Introduction}

Recently, injury to the posteromedial corner (PMC) of the knee has been reported in several research works. Anatomically, the PMC is composed of five major components: the superficial medial collateral ligament (MCL), the deep $\mathrm{MCL}$, the posterior oblique ligament (POL), the posterior horn of the medial meniscus, and the oblique popliteal

\footnotetext{
* Correspondence: osdku@dankook.ac.kr

Department of Orthopaedic Surgery, Dankook University College of Medicine, 119, Dandae-ro, Dongnam-gu, Cheonan-si, Chungnam 330-715, Republic of Korea
}

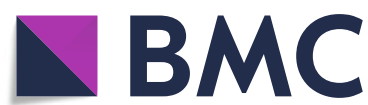

Part of Springer Nature ligament [1-4]. Medial-sided knee injuries are one of the most common knee ligament injuries encountered by orthopedic surgeons. These ligament injuries can occur in isolation or with concomitant meniscal or cruciate ligament injuries $[1,5]$. The PMC functions as a primary stabilizer of the extended knee position: the load-bearing position of the knee in gait. In knee flexion, the PMC acts as a restraint to external rotation. Current biomechanical studies have revealed that the PMC contributes approximately one-third of the restraint to valgus stress in the extended knee $[2,6]$. Furthermore, the posterior horn of

(c) The Author(s). 2020 Open Access This article is licensed under a Creative Commons Attribution 4.0 International License, which permits use, sharing, adaptation, distribution and reproduction in any medium or format, as long as you give appropriate credit to the original author(s) and the source, provide a link to the Creative Commons licence, and indicate if changes were made. The images or other third party material in this article are included in the article's Creative Commons licence, unless indicated otherwise in a credit line to the material. If material is not included in the article's Creative Commons licence and your intended use is not permitted by statutory regulation or exceeds the permitted use, you will need to obtain permission directly from the copyright holder. To view a copy of this licence, visit http://creativecommons.org/licenses/by/4.0/ The Creative Commons Public Domain Dedication waiver (http://creativecommons.org/publicdomain/zero/1.0/) applies to the data made available in this article, unless otherwise stated in a credit line to the data. 
the medial meniscus acts like a "brakestop," providing anterior restraint in the absence of the anterior cruciate ligament (ACL) [7]. The ACL controls anterior movement of the tibia and inhibits extreme ranges of tibial rotation [8]. The ACL is also important in proprioceptive information and stabilization of muscular reflexes via a mechanoreceptor feedback system [9]. Therefore, combined ACL and PMC injuries are serious because the ACL and PMC are secondary stabilizers to each other.

PMC injuries are frequently associated with other ligament injuries such as those of the ACL, posterior cruciate ligament (PCL), or MCL. In the past several decades, PMC injuries have been managed in different ways including surgical or non-surgical treatment [7], and there is still controversy regarding their treatment. However, in recent years, numerous orthopedic surgeons have focused on surgical management for PMC-involved high-energy multiligamentous knee injuries [7, 10-13].

The purpose of the present study was to assess the influence of PMC injuries on clinical outcomes and secondlook arthroscopic findings after ACL reconstruction. The hypothesis of this study was that, at least at the 2-year follow-up, PMC injuries are closely related with graft tension and clinical outcomes after ACL reconstruction.

\section{Materials and methods}

After obtaining approval from our institutional review board, informed consent was obtained from 78 consecutive patients who underwent a second-look arthroscopic surgery after ACL reconstruction and magnetic resonance imaging (MRI) examination from January 2013 to November 2016.

The inclusion criteria were as follows: patients who underwent a second-look arthroscopic surgery after primary single-bundle ACL reconstruction using a modified transtibial technique with an allograft. Patients who had a history of previous surgery on the injured knee, multiligament injuries including the PCL, anterolateral ligament, or lateral collateral ligament, or arthritic changes were excluded. Patients who had an MRI scan more than 4 weeks after the initial trauma or in other hospitals were also excluded.

All surgeries were performed by a single, experienced orthopedic surgeon (HGP), using the modified transtibial technique. The tibial tunnel was made by drilling from the medial aspects of the proximal tibia to the femoral tunnel, using the modified method. The entering point of the tibial tunnel is located at the midpoint between the posterior cortex of the proximal tibia and the medial margin of the tibial tuberosity. A minimal notchplasty was performed to avoid complete removal of the remnant ACL at the tibial attachment site and prevent impingement of the grafted ACL. Since all surgeries were performed by a single surgeon, the remnant preservation was assumed to be the same. When there were meniscal or cartilage lesions, the proper procedure was performed. After forming the tibial tunnel, a transtibial femoral tunnel guide was inserted, and the rear angle of the guide was placed in the 10 o'clock position (right knee) knee or 2 o'clock position (left knee). Then, a tunnel with a depth of $30 \mathrm{~mm}$ and a diameter of $1 \mathrm{~mm}$ less than that of the graft was drilled to achieve approximately $1-2 \mathrm{~mm}$ of the femoral posterior wall. To fix the graft, the RigidFix technique (RigidFix; DePuy Mitek, Inc., Raynham, MA, USA) was used. The tibial tunnel was fixed again by using a post-tie after it was fixed with a bioabsorbable interference screw (Arthrex, Naples, FL, USA).

Joint flexion and extension were allowed starting from the day after surgery. Patients who did not undergo a meniscal repair procedure were allowed to perform partial weight-bearing activities for 2 weeks while wearing an ACL brace. After 2 weeks, full weight bearing was allowed. In patients who had a meniscal repair, partial weight bearing was performed for 6 weeks and the brace was worn for 6 weeks. We allowed jogging 3 months after surgery. Sports activity was allowed 6-9 months after surgery depending on the state of recovery.

MRI evaluations were performed using 3.0 T devices (Philips Achieva, The Netherlands). Our MRI protocol included a coronal T1-weighted sequence; sagittal, axial, and coronal T2-weighted sequences with fat saturation; and a sagittal proton density-weighted sequence. The position of knee in full extension was recommended; however, if the patient was unable to fully extend the knee due to swelling or pain, a slightly flexed position was allowed. Examination results were assessed by two orthopedic surgeons (HGP) and (JYY). We considered a PMC as having a lesion if there was injury to at least one of the PMC structures. We considered lesions to be present if there were signal changes in the MRI or if injuries were found on arthroscopy, even partial injuries. We classified the PMC as normal or as having a lesion [6, 14-17] (Fig. 1).

All the patients underwent a second-look arthroscopy and hardware removal at least 2 years after ACL reconstruction. All patients had given informed consent before surgery. The ACL graft status was evaluated by a single surgeon (HGP). Synovial coverage over the grafts was classified into the following three categories: good (nearly entirely covered), half (>50\%), and pale (no coverage; <50\%; see Fig. 2). Additionally, we used a modification of the classification system for ACL grafts described by Kim et al. to evaluate the tear of graft bundles during second-look arthroscopy [18]. In accordance with this system, the graft tear status was graded as normal (probing, $<2 \mathrm{~mm}$ ), lax (probing, $>2$ but $<5 \mathrm{~mm}$ ), partial tear (probing, $>5 \mathrm{~mm}$ ), and total tear (see Fig. 3). The hardware removal was performed after the ACL 

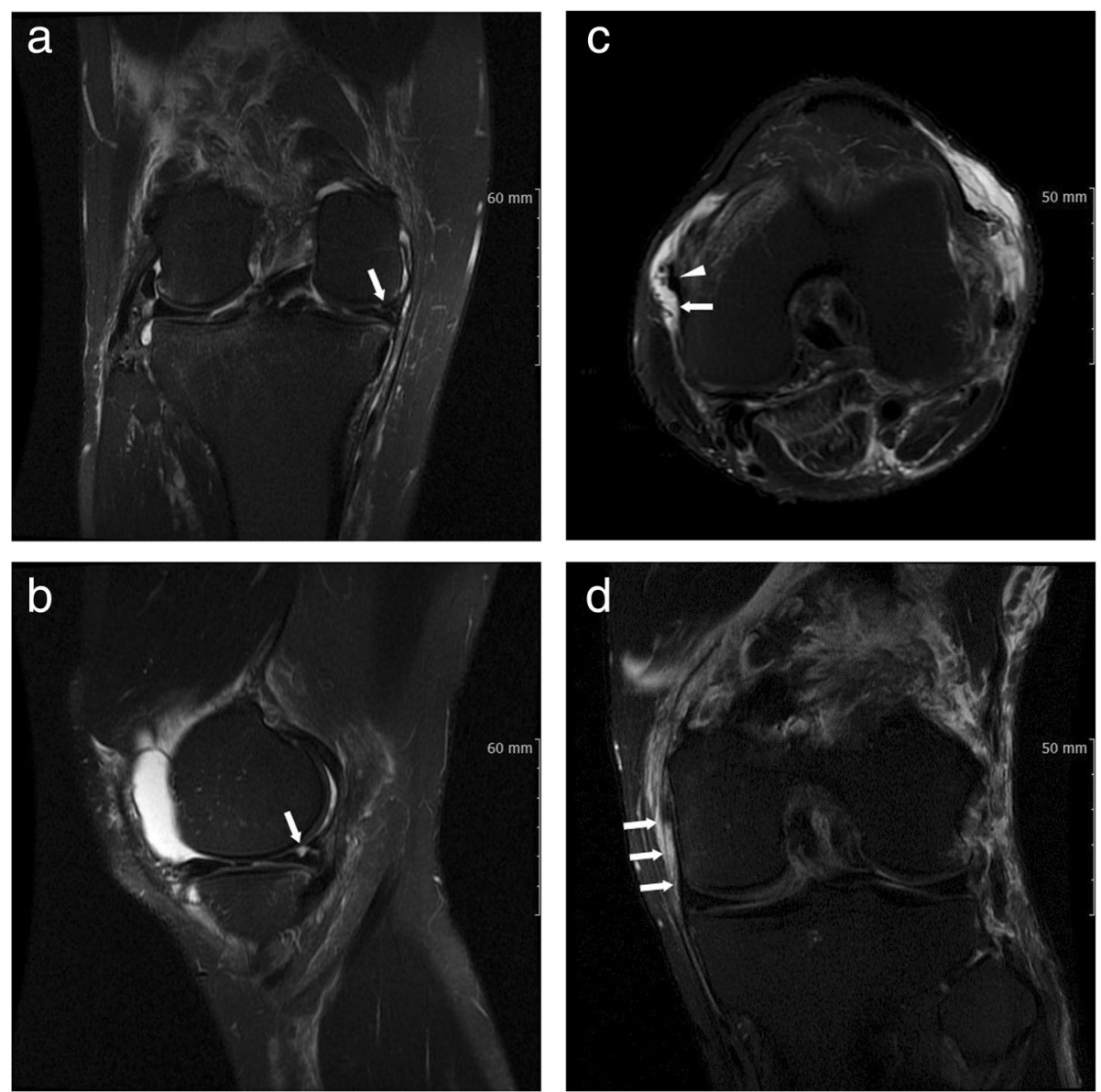

Fig. 1 Magnetic resonance image of posteromedial corner injury. a Coronal fat-suppressed image of medial meniscus, showing complex tear of posterior horn (arrow). b Sagittal fat-suppressed image of medial meniscus, showing complex tear of posterior horn (arrow). c Axial fat-suppressed image of injury to the posterior oblique ligament (POL), showing edema around disrupted POL (arrow) and a normal femoral insertion of medial collateral ligament (arrowhead). d Coronal fat-suppressed image of injury to POL (arrows)

graft evaluation. Two weeks after surgery, running and sports were allowed.

All the patients were clinically evaluated before the initial and 2-year follow-up visits at second-look arthroscopic operation using a KT-2000 arthrometer, the Lachman test, pivot-shift test, and Lysholm knee scoring scale. The KT-2000 arthrometer test was performed at 30lbs to measure side-to-side difference in anterior translation with the knee positioned at $20^{\circ}$ of flexion. In the pivot-shift test, the knee was graded as normal, close to normal, and abnormal. The Lachman test and pivot-shift test were perfomed by a single surgeon (HGP). The Lysholm knee scoring scale was used for general evaluation of the knee [19].

To evaluate the normal distribution of the continuous data, the Kolmogorov-Smirnov test was performed, the continuous variable was analyzed using an independent $t$ test, and the non-continuous variable was analyzed using the Pearson chi-square test. All statistical analyses were performed using the Statistical Package for Social
Sciences version 20.0 (SPSS, Inc., an IBM Co., Chicago, IL, USA). Statistical significance was considered at a $p$ value of $<0.05$ for all the analyses.

\section{Results}

Of the 78 patients included in this study, there were 42 patients with intact PMCs and 36 patients with injured PMCs. There was no significant difference between the two groups with respect to age, sex, body mass index, mean duration to follow-up second-look arthroscopy, location of meniscal tears, or surgical treatment for the meniscus (see Table 1).

All patients undergoing meniscus repair were well healed without re-tear, and ACL grafts in all patients had no partial or total tears.

Of the 42 patients in the PMC intact group, 24 (57.1\%) showed a good synovial coverage, 18 (42.9\%) showed half synovial coverage, and none showed pale synovial coverage. Of the 36 patients in the PMC injured group, 30 (83.3\%) showed a good synovial coverage, 6 

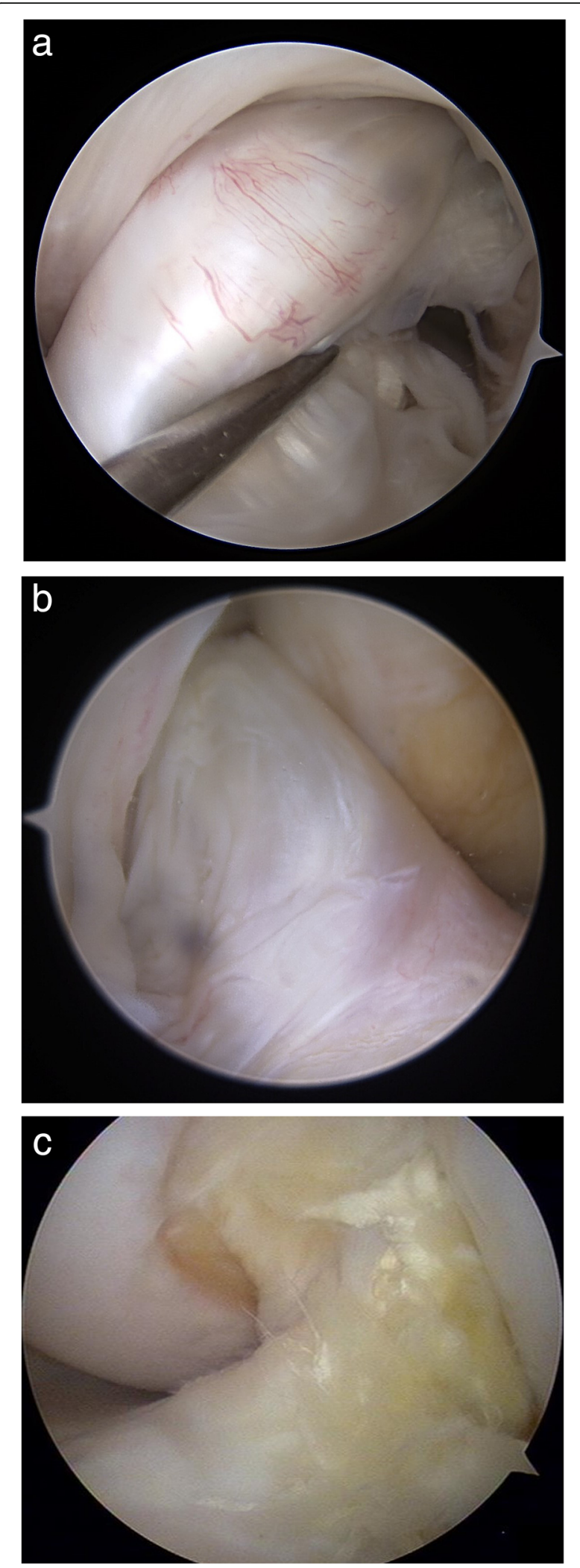

Fig. 2 Classification of synovial coverage. a Good (nearly entirely covered); b half synovialization (> 50\%); c pale (no coverage; $<50 \%$ )
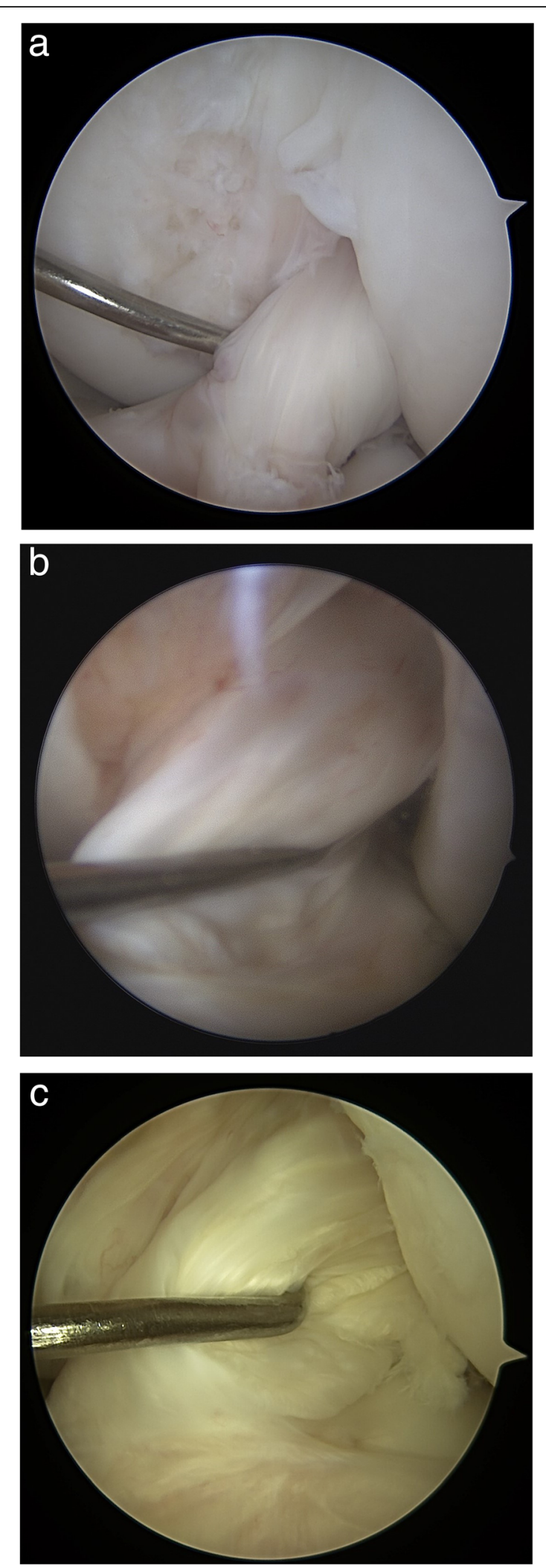

Fig. 3 Classification of graft tension. a Normal (probing, $<2 \mathrm{~mm}$ ); b lax (probing, $>2 \mathrm{~mm}$ but $<5 \mathrm{~mm}$ ); c partial tear (probing, $>5 \mathrm{~mm}$ ) 
Table 1 Demographic data

\begin{tabular}{llll}
\hline & $\begin{array}{l}\text { PMC intact } \\
\text { group } \\
(n=42)\end{array}$ & $\begin{array}{l}\text { PMC injured } \\
\text { group } \\
(n=36)\end{array}$ & $P$ \\
\hline Age & 31.9 & 29.2 & n.s. \\
Sex (male:female) & $19: 2$ & $7: 2$ & n.s. \\
Body mass index & 25.0 & 24.2 & n.s. \\
Mean follow-up to second-look & 27.4 & 25.9 & n.s. \\
arthroscopy (months) & $2^{\text {a }}$ & 24 & n.s. \\
Medial meniscus tear & 10 & 12 & n.s. \\
Lateral meniscus tear & 0 & 2 & n.s. \\
Medial and lateral & & & \\
meniscus tear & 4 & 12 & n.s. \\
Meniscectomy & 2 & 10 & n.s. \\
Meniscus repair &
\end{tabular}

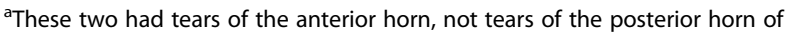
the medial meniscus

(16.7\%) showed half synovial coverage, and none showed pale synovial coverage. Synovial coverage in association with PMC injuries showed a statistically significant difference between the two groups (see Table 2). The PMC injured group showed poor synovial coverage.

Of the 42 patients in the PMC intact group, 36 (85.7\%) showed a normal graft, 6 (14.3\%) showed a lax graft, and none had partial or total tears. Of the 36 patients in the PMC injured group, 26 (72.2\%) showed a normal graft, $10(27.8 \%)$ showed a lax graft, and none had partial or total tears. Graft tension showed no statistically significant difference between the two groups (Table 2).

The mean postoperative Lysholm scores were, respectively, 92.8 and 93.9 for the PMC intact group and the PMC injured group. The mean KT-2000 arthrometer values were similar at both pre-operation and at the 2year follow-up, but no statistical difference was found between the groups. Furthermore, the Lachman test and pivot-shift test showed statistically comparable results. However, there was no statistically significant difference

Table 2 Arthroscopic findings following PMC injury

\begin{tabular}{llll}
\hline & $\begin{array}{l}\text { PMC intact } \\
\text { group } \\
(n=42)\end{array}$ & $\begin{array}{l}\text { PMC injured } \\
\text { group } \\
(n=36)\end{array}$ & $P$ \\
\hline $\begin{array}{llll}\text { Tension } \\
\text { Normal }\end{array}$ & $\begin{array}{l}36(85.7 \%) \\
\text { Lax }\end{array}$ & $26(72.2 \%)$ & 0.141 \\
$\quad$ Partial tear & 0 & $10(27.8 \%)$ & \\
Complete tear & 0 & 0 & 0.012 \\
Synovial coverage & & 0 & \\
Good & $24(57.1 \%)$ & $30(83.3 \%)$ & \\
Half & $18(42.9 \%)$ & $6(16.7 \%)$ & \\
Pale & 0 & 0 & \\
\hline
\end{tabular}

in clinical outcomes (see Table 3). Also, the correlation between the Lachman test and graft tension was not significant.

Of the 78 patients, there were 20 patients with an injured MCL, 9 with POL injuries, 24 patients with an injured posterior horn of the medial meniscus, and 6 with oblique popliteal ligament injuries (see Table 4).

\section{Discussion}

The MCL provides the primary valgus restraint in the flexed knee and is an external rotation stabilizer [20,21]. With extension, the PMC becomes the primary stabilizer to valgus stress and prevents posterior tibial translation $[2,3,6,7]$. Consequently, PMC injuries combined with ACL injuries are significantly different and more serious than isolated ACL rupture and make the knee unstable in valgus motion and rotations. To the best of our knowledge, this study is the first to evaluate the influence of PMC injuries on second-look arthroscopic findings after $\mathrm{ACL}$ reconstruction.

In this study, there was poor synovial coverage at the second-look arthroscopic examination in the PMC injured group. Synovialization is an important factor in

Table 3 Clinical outcomes comparison

\begin{tabular}{|c|c|c|c|}
\hline & $\begin{array}{l}\text { PMC intact } \\
\text { group } \\
(n=42)\end{array}$ & $\begin{array}{l}\text { PMC injured } \\
\text { group } \\
(n=36)\end{array}$ & $P$ \\
\hline Mean last Lysholm score & 92.8 & 93.9 & n.s \\
\hline \multicolumn{4}{|l|}{ Mean KT-2000 } \\
\hline Pre-operation & 4.9 & 4.7 & n.s \\
\hline Last follow-up & 1.5 & 1.2 & n.s \\
\hline \multicolumn{4}{|l|}{ Lachman test } \\
\hline Pre-operation & & & n.s \\
\hline Normal & 4 & 6 & \\
\hline Close to normal & 2 & 2 & \\
\hline Abnormal & 36 & 28 & \\
\hline Last follow-up & & & n.s \\
\hline Normal & 32 & 34 & \\
\hline Close to normal & 10 & 2 & \\
\hline Abnormal & 0 & 0 & \\
\hline \multicolumn{4}{|l|}{ Pivot-shift test } \\
\hline Pre-operation & & & n.s \\
\hline Normal & 4 & 6 & \\
\hline Close to normal & 8 & 6 & \\
\hline Abnormal & 30 & 24 & \\
\hline Last follow-up & & & n.s \\
\hline Normal & 42 & 36 & \\
\hline Close to normal & 0 & 0 & \\
\hline Abnormal & 0 & 0 & \\
\hline
\end{tabular}


Table 4 Distribution of the injured structure of PMC

\begin{tabular}{ll}
\hline Injured structure & 20 \\
\hline Medial collateral ligament & 9 \\
Posterior oblique ligament & 24 \\
Posterior horn of medial meniscus & 6 \\
\hline
\end{tabular}

graft healing and survival of the graft, and thus laxity. It is necessary to restore proprioception, because most of the mechanoreceptors of the ACL are found in the subsynovial layer $[9,22]$. Thus, preservation of the synovium and promotion of synovialization of the graft after ACL reconstruction are considered to be important in restoring proprioceptive function. According to a study by Katayama et al. [23], stability was associated with proprioceptive function. The authors thought that PMC injuries could decelerate synovial coverage of the reconstructed ACL because PMC injuries usually lead to valgus instability.

However, clinical outcomes showed no significant difference between both groups. These results showed that clinical outcomes did not entirely reflect graft state in second-look arthroscopic examinations, because clinical outcome is the result of a combination of various conditions, although synovial coverage is one of the most important factors.

Bollen et al. [24] reported 183 cases of ACL reconstructed knee, of which 9.3\% were PMC injured. Our study had 36 cases (46\%) that were PMC injured. Pandey et al. [7] reported 35 patients with MCL-PMC injury, of whom 20 patients had ACL injuries. They reported that primary MCL-PMC repair renders the knee stable and provides a superior clinical outcome. In our study, ACL was reconstructed but PMC was conserved.

There are several limitations to the present study. First, this study is a retrospective, not a case-controlled, study. Second, we also presumed that preoperative clinical stability would be influenced by PMC injury, but the results showed no difference-not only postoperatively in the ACL reconstructed knee but also preoperatively in the ACL deficient knee. This can be demonstrated by the selection bias: in this study ACL reconstruction was performed in the cases with persistent instability, and stable ACL deficient knees without PMC injury were excluded. Third, the influence of PMC injuries on ACL reconstruction failure could not be analyzed. In the present study, none of the cases had total rupture of the ACL graft because all re-ruptured cases were excluded in line with the exclusion criteria. Fourth, proprioception testing according to synovialization was not conducted. Only synovialization was assessed by arthroscopy. Further studies to evaluate the relationship between the extent of synovialization and proprioception may be needed. Fifth, the extent of remnant ACL preservation may affect synovial coverage, but this was not considered. Since all surgeries were performed by a single surgeon, the remnant preservation was assumed to be the same. Sixth, the degree of meniscectomy and valgus instability at final follow-up in an MCL injured patient can affect ACL graft healing, but this was not considered. Further studies to evaluate the relationship between degree of meniscectomy and valgus instability may be needed.

\section{Conclusion}

Patients who injured the PMC had poor synovial coverage in the second-look arthroscopic examination after transtibial ACL reconstruction. However, there were no significant differences in clinical outcomes and stability.

\section{Abbreviations}

ACL: Anterior cruciate ligament; ALL: Anterior lateral ligament; MCL: Medial collateral ligament; MRI: Magnetic resonance imaging; PMC: Posteromedial corner

\section{Acknowledgements \\ The authors would like to thank the reviewers for reviewing this article}

\section{Dissemination}

Each author represents that the article is original, that it is not under consideration by another journal, and that it has not been previously published. In consideration of the Knee Surgery \& Related Research review and editing of our submission, the authors undersigned hereby transfer, assign, and otherwise convey all copyright ownership to the journal Knee Surgery \& Related Research and represent that they own all rights to the material submitted. This assignment is to take effect only if the work is published in the journal.

\section{Authors' contributions}

HGP developed the concept, provide data analysis, and wrote the manuscript. HGP, JYY, and SMK analyzed the data. JYY and SMK edited the manuscript. Each author certifies that he or she has participated sufficiently in the preparation of this article and has read and agreed with the contents of the final manuscript.

\section{Funding}

The authors or their institutions did not receive any support (e.g., grants, funding, payment, or other benefits) or a commitment or agreement to provide such benefits, in connection with the research or preparation of this manuscript, except as disclosed on a separate attachment.

\section{Availability of data and materials \\ The data and materials that support the findings of this study are openly available.}

Ethics approval and consent to participate

This retrospective study was approved by the Ethics Committee of Dankook University Hospital.

\section{Consent for publication}

Patients understand that the text and any pictures published in the article will be freely available on the Internet and may be seen by the general public. The pictures, videos, and text may also appear on other websites or in print, may be translated into other languages, or used for commercial purposes.

Competing interests

The authors declare that they have no competing interests. 
Received: 10 November 2019 Accepted: 21 July 2020

Published online: 10 August 2020

\section{References}

1. Cinque ME, Chahla J, Kruckeberg BM, DePhillipo NN, Moatshe G, LaPrade RF (2017) Posteromedial corner knee injuries: diagnosis, management, and outcomes: a critical analysis review. JBJS Rev 5(11):e4

2. Elliott M, Johnson DL (2015) Management of medial-sided knee injuries. Orthopedics 38(3):180-184

3. Dold AP, Swensen S, Strauss E, Alaia M (2017) The posteromedial corner of the knee: anatomy, pathology, and management strategies. J Am Acad Orthop Surg 25(11):752-761

4. Bauer KL, Stannard JP (2013) Surgical approach to the posteromedial corner: indications, technique, outcomes. Curr Rev Musculoskelet Med 6(2):124-131

5. Grant JA, Tannenbaum E, Miller BS, Bedi A (2012) Treatment of combined complete tears of the anterior cruciate and medial collateral ligaments. Arthroscopy 28(1):110-122

6. Chahal J, Al-Taki M, Pearce D, Leibenberg A, Whelan DB (2010) Injury patterns to the posteromedial corner of the knee in high-grade multiligament knee injuries: a MRI study. Knee Surg Sports Traumatol Arthrosc 18(8):1098-1104

7. Pandey V, Khanna V, Madi S, Tripathi A, Acharya K (2017) Clinical outcome of primary medial collateral ligament-posteromedial corner repair with or without staged anterior cruciate ligament reconstruction. Injury 48(6):1236-1242

8. Siegel L, Vandenakker-Albanese C, Siegel D (2012) Anterior cruciate ligament injuries: anatomy, physiology, biomechanics, and management. Clin J Sport Med 22(4):349-355

9. Lee BI, Min KD, Choi HS, Kwon SW, Chun DI, Yun ES et al (2009) Immunohistochemical study of mechanoreceptors in the tibial remnant of the ruptured anterior cruciate ligament in human knees. Knee Surg Sports Traumatol Arthrosc 17(9):1095-1101

10. Prince MR, Blackman AJ, King AH, Stuart MJ, Levy BA (2015) Open anatomic reconstruction of the medial collateral ligament and posteromedial corner. Arthrosc Tech 4(6):e885-e890

11. Lubowitz JH, MacKay G, Gilmer B (2014) Knee medial collateral ligament and posteromedial corner anatomic repair with internal bracing. Arthrosc Tech 3(4):e505-e508

12. DeLong JM, Waterman BR (2015) Surgical techniques for the reconstruction of medial collateral ligament and posteromedial corner injuries of the knee: a systematic review. Arthroscopy 31(11):2258-72..e1

13. Stannard JP, Black BS, Azbell C, Volgas DA (2012) Posteromedial corner injury in knee dislocations. J Knee Surg 25(5):429-434

14. Loredo R, Hodler J, Pedowitz R, Yeh LR, Trudell D, Resnick D (1999) Posteromedial corner of the knee: MR imaging with gross anatomic correlation. Skelet Radiol 28(6):305-311

15. House CV, Connell DA, Saifuddin A (2007) Posteromedial corner injuries of the knee. Clin Radiol 62(6):539-546

16. Craft JA, Kurzweil PR (2015) Physical examination and imaging of medial collateral ligament and posteromedial corner of the knee. Sports Med Arthrosc Rev 23(2):e1-e6

17. Sims WF, Jacobson KE (2004) The posteromedial corner of the knee: medialsided injury patterns revisited. Am J Sports Med 32(2):337-345

18. Kim MK, Lee SR, Ha JK, Ra HJ, Kim SB, Kim JG (2014) Comparison of secondlook arthroscopic findings and clinical results according to the amount of preserved remnant in anterior cruciate ligament reconstruction. Knee 21(3): 774-778

19. Lysholm J, Gillquist J (1982) Evaluation of knee ligament surgery results with special emphasis on use of a scoring scale. Am J Sports Med 10(3):150-154

20. Azar FM (2006) Evaluation and treatment of chronic medial collateral ligament injuries of the knee. Sports Med Arthrosc Rev 14(2):84-90

21. Fanelli GC, Harris JD (2006) Surgical treatment of acute medial collateral ligament and posteromedial corner injuries of the knee. Sports Med Arthrosc Rev 14(2):78-83

22. Noh JH, Yang BG, Roh YH, Lee JS (2011) Synovialization on second-look arthroscopy after anterior cruciate ligament reconstruction using Achilles allograft in active young men. Knee Surg Sports Traumatol Arthrosc 19(11): 1843-1850
23. Katayama M, Higuchi H, Kimura M, Kobayashi A, Hatayama K, Terauchi M et al (2004) Proprioception and performance after anterior cruciate ligament rupture. Int Orthop 28(5):278-281

24. Bollen SR (2010) Posteromedial meniscocapsular injury associated with rupture of the anterior cruciate ligament: a previously unrecognised association. J Bone Joint Surg Br 92(2):222-223

\section{Publisher's Note}

Springer Nature remains neutral with regard to jurisdictional claims in published maps and institutional affiliations.
Ready to submit your research? Choose BMC and benefit from:

- fast, convenient online submission

- thorough peer review by experienced researchers in your field

- rapid publication on acceptance

- support for research data, including large and complex data types

- gold Open Access which fosters wider collaboration and increased citations

- maximum visibility for your research: over $100 \mathrm{M}$ website views per year

At BMC, research is always in progress.

Learn more biomedcentral.com/submissions 